\title{
UN LIENZO DE SANTA CATALINA DE SIENA DE VICENTE MALÓ
}

Tratando este lienzo con ocasión al estudio de algunas determinadas pinturas de Cornelio de Vos en estas páginas ${ }^{1}$, creo oportuno considerar la atribución del lienzo de Santa Catalina de Siena de colección privada, que estimo atribuible a Vicente Maló, un pintor con escasa producción en el coleccionismo español ${ }^{2}$, y vinculado a la ciudad de Génova, donde trabaja y abunda su obra ${ }^{3}$. La factura blanda coincide con el estilo de Cornelio de Vos, y algún sutil recurso en la concepción del claroscuro. De hecho es un seguidor de Rubens a extramuros. La composición y modelos recuerdan típicas fórmulas del maestro, pero la atmósfera densa y la uniformidad tonal nos avisa de maneras vinculables al barroco italiano.

Los rostros llenos, nariz corta y afilada y los modelos de los angelitos son reconocibles en obras de su mano. Los ritmos ondulantes y modelos están en la Santa Cena de colección privada de Génova, firmada con anagrama, y recientemente expuesta ${ }^{4}$. El pintor centra el ramillete de angelitos con igual fórmula convexa en el eje central de la composición, en un rompimiento de gloria dorada, sobre un interior de arquitectura monumental. Nosotros vemos paralelismos con esta Santa Cena, con escenas complementarias en los segundos planos, y gusto por la naturaleza muerta, que se despliega con generosidad en las mesas de una y otra obra.

Vicente Maló fue también pintor de paisajes y de escenas de género y es de suponer también de bodegones, de éstos fue especialista su discípulo Isaac Wigen que le acompañó a Italia ${ }^{5}$.

El asunto no es fácil de identificar, no figura en la obra de L. Reau al tratar la vida de la Santa. Aparentemente, la protagonista parece ser la mujer sentada a la derecha, llevando su mano al pecho sobre una cruz de rica pedrería, y con la mirada vuelta agradecida hacia la que sirve la bandeja con frutas. Ésta, de pie y de perfil semioculto en la penumbra (pues la luz va de derecha a izquierda), es Santa Catalina de Siena. La indumentaria sobria y los comedidos gestos concuerdan con la imagen que nos transmite la literatura devota. Ningún signo sacral identifica su personalidad. Trata de una historia de escasa divulgación de su vida: la ayuda que presta a una joven enferma que acoge en su casa, ofrece su ayuda y mima en extremo, recibiendo ingratitud e incomprensión. La Santa no tuvo estos comportamientos en consideración, respondiendo con la generosidad de su alma ${ }^{6}$. La secuencia del fondo corresponde al recibimiento de esta mujer. Pensamos es la misma mujer que encontramos en la mesa vestida ricamente, lleva un mismo collar de perlas y pendientes iguales. En el fondo un ángel mancebo acompaña con un laúd la comida de la invitada ${ }^{7}$.

La inscripción en un papel debajo de la mesa lleva el nombre de la Santa, que ayuda al reconocimiento de la historia: OHNUASCOTTAS. CATHRINE SENENSI IN PROPTYS EDIBUS INSERVIENS SIBI POSTERIATIQUE SUE VOCE ET SCRIPTO PROMISS PROTECTIONE DITATUI (Figs. 9 y 10). La ingratitud no engaña al animal.

1 Nuevas pinturas de Cornelio de Vos identificadas en colecciones españolas y extranjeras, Archivo Español de Arte LIX, 1986, p. 181.

2 Díaz Padrón, M.: La pintura flamenca del S. XVII en España, n. ${ }^{\circ} 628,1976$, II, p.

3 Soprani, R.: «Le Vite dé pittori Scultori et Architetti, genovesi e dé Forasteri, che in Génova. Opera mss. Romae con Aleuni Riltratti de gli stessi», 1674, p. 330.

${ }^{4}$ Génova nell'Etta Barocca, p. 223, n. ${ }^{\circ} 122$.

5 Benezit, E.: Dictionnaire des peintres, Sculpteurs, dessinateurs et graveurs, 1966, VIII, p. 741.

6 Réau, L.: Iconográphie de L'arte chrétien, 1958, III, I, p. 272.

7 Enciclopedia Universal Ilustrada. Espasa-Calpe, 1958, XII, p. 448. 

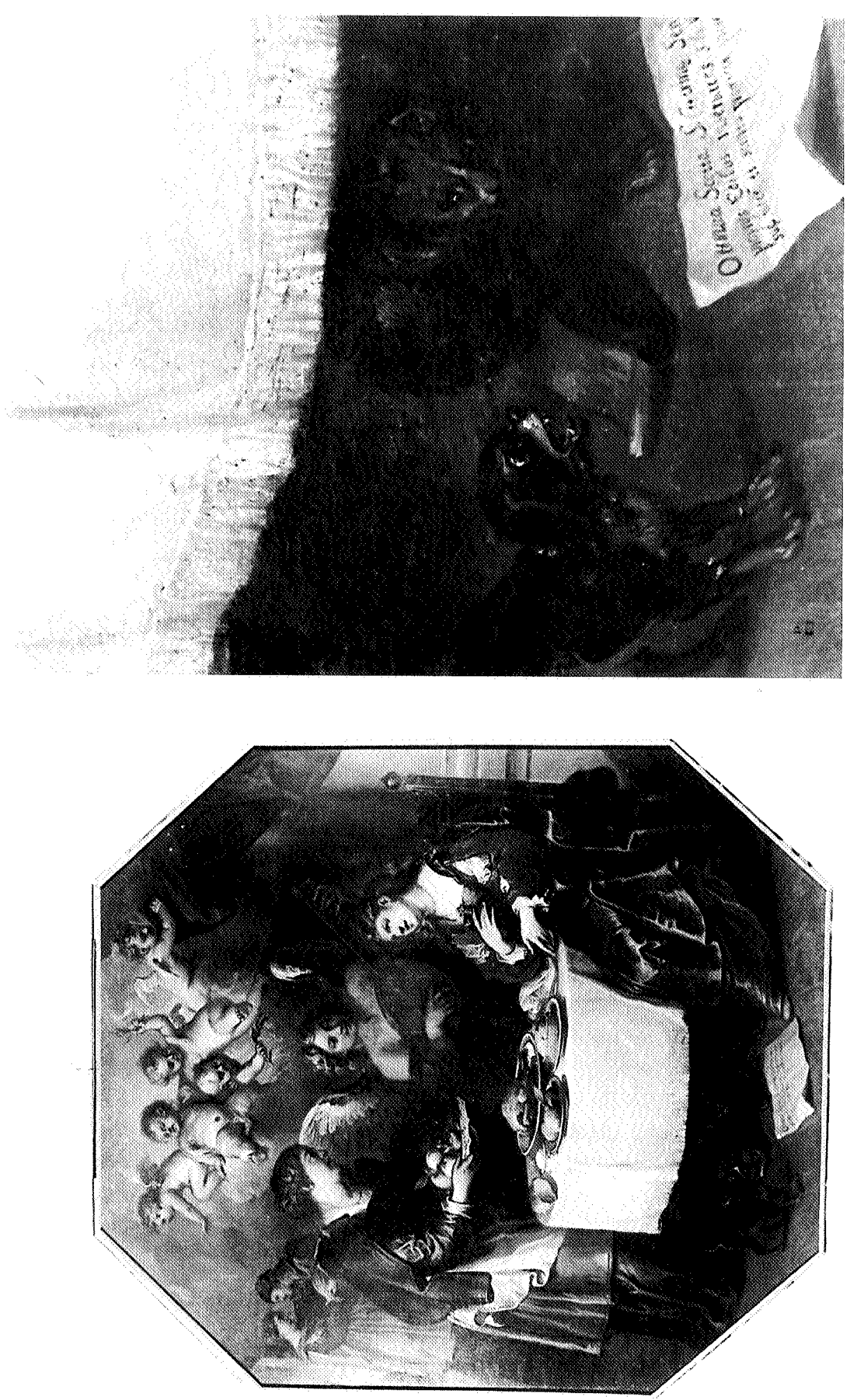

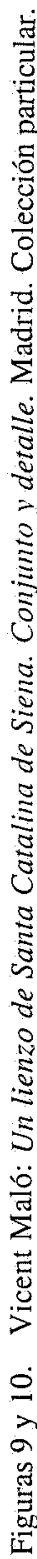


Un gato y un perro están juntos debajo de la mesa y junto al documento. Tiene intencionalidad en el contexto de la historia. El perro, que se vuelve ladrando crispado hacia la invitada.

Su lujoso vestido contrata con el de la Orden Dominicana, que vivió en el siglo XIV.

$\mathrm{Su}$ culto se centra con prioridad en Italia. El lienzo es de gran tamaño y formato ochavado (L. $225 \times 205$ ).

\section{MATÍAS DÍAZ PADRÓN}

Museo del Prado

\section{UN VALDÉS LEAL EN EL CAMPO DE GIBRALTAR}

En la iglesia de Santa María Coronada de San Roque (Cádiz) hay un cuadro que representa la Predicación del Bautista y forma pendant con otro lienzo de diferentes caracteres estilísticos, con el que ni siquiera tiene correspondencia iconográfica ${ }^{1}$. Se desconoce su procedencia, habiendo pasado desapercibido para cuantos se han ocupado del edificio y de sus obras de arte. Sin embargo, puede asegurarse que no fue ejecutado expresamente para dicho templo, por tratarse de una construcción de principios del siglo XVIII que heredó las funciones y algunos bienes de la extinta parroquia gibraltareña, a la que en todo caso hubiera correspondido el encargo ${ }^{2}$. Da la impresión de que, al igual que el compañero, ha sido forzado para ajustarlo a un nuevo marco de menores dimensiones que el original ${ }^{3}$ (Fig. 11).

Tras un detenido examen visual hemos llegado a la conclusión de que pertenece a Valdés Leal (1622-1690) y que puede tratarse de la obra que Justino Matute situó junto al altar mayor de la capilla de los Vizcaínos, en el desaparecido convento sevillano de San Francisco. A Matute le llamó la atención «la expresión e intereses de dos fariseos que le escuchan [al Bautista] en el primer término»: un comentario que bien podría aplicarse al lienzo sanroqueño ${ }^{4}$ (Figs. 11, 14 y 15 ).

1 Se trata de una Ascención de la Virgen, pintada por un excelente maestro zurbaranesco.

2 En ningún inventario de los objetos sacados de Gibraltar, tras la pérdida de la plaza, se menciona el cuadro. Cfr. Caldelas López, Rafael: La parroquia de Gibraltar en San Roque (Documentos 1462-1853). Cádiz, 1976 , pp. 89 y ss. Este mismo investigador local, párroco de la iglesia durante décadas, nos comunicó que desconocía el origen del cuadro, aunque previsiblemente fue legado por un anónimo feligrés.

3 Mide 2,85 x 1,76 m. Agradecemos la ayuda que en su momento nos ofrecieron don Enrique Valdivieso y el desaparecido don Juan Miguel Serrera, para la confirmación de la autoría del cuadro; asimismo la generosa colaboración del señor párroco don Sebastián Araujo y la de don Juan José López Pomares, quẹ nos proporcionó las fotografías que acompañan al texto.

4 Matute y Gaviria, Justino: «Adiciones y Correcciones de d. Justino Matute al tomo IX del Viaje de España de D. Antonio Ponz». Archivo Hispalense, III (1887, reed. 1987). Carta III, n. ${ }^{\circ} 37$, p. 368. El tema no es desconocido dentro de la producción de Valdés Leal. Se sabe que hacia 1675 pintó para el capitán don Juan José de Bárcena la vida de San Juan Bautista en siete episodios. En mayo de 1676 el pintor otorga carta de pago por dicha serie, que se encontraba en poder de Bárcena al menos un año antes. Se mantuvo completa durante todo el siglo XVIII, pasando al final del mismo a manos del oidor don Francisco de Bruna y Ahumada. A la muerte de este ilustre personaje sevillano se dispersó, ingresando algunos de los cuadros en la colección de José de Madrazo y luego en la del marqués de Salamanca hasta que en 1881 fueron vendidos. Cfr.: Gestoso, José: Biografía del pintor sevillano Juan de Valdés Leal. Sevill, 1916, p. 133; Romero Murube, Joaquín: Francisco de Bruna y Ahumada. Sevilla, 1965, p. 116, n. ${ }^{\circ}$ 30; Kinkead, Duncan T.: «Artistic inventories in Sevilla: 1650-1699». Boletín de Bellas Artes, XVII (Sevilla, 1989), p. 130, 50a; Pérez Sánchez, Alfonso E.: Pintura española recuperada por el coleccionismo privado. Madrid, 1996, p. 148. 